Marquette University

e-Publications@Marquette

Marketing Faculty Research and Publications

Marketing, Department of

$1-1-2010$

\title{
Diagnosing Service Quality in Retailing: The Case of Singapore
}

Srinivas Durvasula

Marquette University, srinivas.durvasula@marquette.edu

Steven Lysonski

Marquette University, steven.lysonski@marquette.edu

Published version. Journal of International Business and Entrepreneurship Development, Volume 5, No. 1 (2010), DOI: 10.1504/JIBED.2010.035196. (C) 2010 Inderscience. Used with permission. 


\title{
Diagnosing service quality in retailing: the case of Singapore
}

\author{
Department of Marketing, \\ College of Business, \\ Marquette University, \\ Milwaukee, WI, 53233, USA \\ E-mail: Srinivas.durvasula@marquette.edu \\ E-mail: s.lysonski@marquette.edu \\ *Corresponding author
}

Srinivas Durvasula* and Steven Lysonski

\begin{abstract}
This paper examines the service quality perceptions of consumers towards retailers in Singapore. We applied SERVQUAL, a popular measure of service quality to a sample of 172 consumers to assess service quality perceptions, expectations and gaps in service quality. We first examined the dimensionality and reliability of this scale. Subsequently, analysis by various demographic groups revealed significant gaps in service quality; the gaps in quality were much higher for some service quality dimensions than for others. The implications of these results for Singapore retailers and retail entrepreneurs are then presented along with future research directions.
\end{abstract}

Keywords: retailing; SERVQUAL; service quality; Singapore.

Reference to this paper should be made as follows: Durvasula, S. and Lysonski, S. (2010) 'Diagnosing service quality in retailing: the case of Singapore', J. International Business and Entrepreneurship Development, Vol. 5, No. 1, pp.1-17.

Biographical notes: Srinivas Durvasula is a Professor and the Edward A. Brennan Chair in Marketing at Marquette University in Wisconsin. His research interests include modelling, measurement theory and cross-national studies of consumers. His research has appeared in journals such as the Journal of Consumer Research, Journal of Marketing Research, Journal of International Business Studies, Journal of Retailing, Journal of Advertising, Journal of Public Policy and Marketing and Journal of Consumer Affairs.

Steven Lysonski is a Professor of Marketing and a Miles Research Scholar at Marquette University in Wisconsin. His research interests are in the areas of cross-cultural marketing, product management and consumer behaviour. His research has appeared in journals such as the Journal of Marketing, Journal of Consumer Research, Journal of International Business Studies, Journal of Consumer Affairs, Journal of Product Management, Journal of Advertising and the International Journal of Research in Marketing. 


\section{Introduction}

Whether it is in North America, Europe or Australia, the scenario faced by most of the free market economies of the world is the same. The explosive growth of urban and suburban shopping centres has resulted in a saturation of the retail environment, leading to intense competition among retailers. Due to economic fluctuations, changes in consumer demographics and the availability of alternative means of purchasing (e.g., via direct marketing and online internet shopping), retailers are finding it hard to gain consumer patronage. A major goal of this paper is to examine how effective Singaporean retailers have been in satisfying the quality expectations of their customers. Insight from this investigation can aid retailing entrepreneurs who either aim to start a retail operation or wish to develop a more effective retailing mix for their existing business.

Singapore's retail landscape has witnessed dramatic changes since the 1960 s due to its economic growth and social development (Keri, 1993). The Singapore Government played a major role in helping the retail sector become modern and attractive to domestic and overseas shoppers. As the retail market in Singapore continues to mature, retailers must be vigilant to understand the mindset of the shopper. The contemporary retail market can be described as highly cosmopolitan, complex and sophisticated, as evidenced by the presence of almost every international brand and multinational retailer (Yap, 1996). Within this accelerating competitive environment, the typical person in Singapore has been transformed into a well-informed customer with clearly defined preferences. As such, retailing entrepreneurs face a more challenging environment in Singapore compared to only a decade ago.

In 2005, employment at the retail level exceeded 90,000 workers with total sales of $\$ 21$ billion (Singapore dollars). Moreover, retail sales are growing at about $12 \%$ per year. Singapore's retail environment is dynamic and vibrant as reflected by the opening of new shopping malls in addition to the extensive modernisation of existing shopping centres such as Raffles City, Marina Square and the Centerpoint. Adding to this dynamism and vibrancy is the opening of stores by international brands such as GAP, Banana Republic and River Island. The outcome of these new malls and stores is intense competition and immense retail space.

The retail market has become saturated with competitors offering duplication of products and similar retailing formats (Yap, 1996). The need to develop a more differentiated offering has been a chief concern among retailers in Singapore and for entrepreneurs who enter this market space. While the challenge for retailers is to give consumers what they want, discovering these wants is problematic. The saturation of the retail environment in Singapore has lead to a shakeout in the industry, forcing out weaker retailers. One way for retailers to stay on top of the competition is to provide a better quality of service, resulting in a differentiated offering. In fact, previous studies have shown that service quality has a significant effect on market share and return on investment (e.g., Anderson and Zeithmal, 1984; Phillips et al., 1983). Positive consumer perceptions of service quality also contribute to enhanced service satisfaction (Mehta and Durvasula, 1998). Clearly, service quality has become an essential driver in generating increased revenues and loyal customers.

Boon (2007) exhorts retailers to adapt to the new retail environment by developing strategies that will enhance a customer's shopping experience through better customer service and upgrading the skills (through training) of front line workers who serve 
customers. He maintains that retailers must give customers a unique, delightful and unforgettable shopping experience while making sure that retail workers are well-trained in understanding customer needs and can give impeccable service. Indeed, retailing is not just about providing the right mix of products; it also deals with giving customers 'wow' experiences that they will remember and cherish. Azhar (2005) argues that the essential strategic consideration is to find other means to engage the customer beyond low prices. Engaging customers requires understanding how they perceive quality in the retail setting. Ibrahim and $\mathrm{Ng}$ (2002), for example, found that high quality service and entertaining shopping experience were strongly associated with increased patronage by shoppers.

\section{Globalisation of retailing and challenges faced by retailing entrepreneurs}

In the past decade, the globalisation of retailing has become noteworthy. Well-known retailers have ventured to foreign markets in search of profits given the saturation of their own domestic market. Well-known retailers such as Wal-Mart, Gap, Disney, Starbucks and Best Buy among many others are now deriving significant revenues from overseas operations. The trend is likely to continue. In this climate, the retailing sector has become one of the most rapidly growing sectors of the economies of developing and developed countries (Kearney, 2005). With the expansion of purchasing power by consumers in developed and developing countries, the retailing sector is expected to continue to thrive in the long-term. For this main reason, the retailing industry continues to attract significant investments by both domestic and foreign retailers. According to the Global Entrepreneurship Monitor Report (2006), the largest share of early-stage entrepreneurs and established business owners is active in consumer oriented sectors such as retailing. This trend is certainly visible in Singapore. A study conducted by the National University of Singapore's entrepreneurship centre shows that the retailing sector in Singapore is drawing sizeable new investments. Along with hotels and restaurants, the retailing sector's share of new investments from angel investors was 39\% in 2004 (vs. 24\% in other countries) (Kam and Ping, 2004) and over 50\% in 2005 (Wong et al., 2006).

While these statistics point to an increase in domestic retailing, smaller retailers in general are facing increasing competition from big multinational retailers. Many of these small retailers are owned by entrepreneurs. There is a growing perception that multinational retailers dominate domestic retailers by offering lower prices through efficient distribution of goods and services and consistent quality through standardisation. Small retailers find it difficult to match the supply chain efficiencies and purchasing leverage enjoyed by the big retailers that have enormous scope. It is felt that offering superior quality products at lower prices would not have been possible without the presence of multinational retailers (Gamble and Huang, 2008). The end result is that customers have become accustomed to superior retail formats of multinational retailers and have begun to demand better prices and superior customer service from both domestic and foreign retailers. In China, for example, domestic retailers in the past often used to ignore customers. This practice has begun to change once the multinational retailers opened outlets in China and customers started appreciating superior service quality from foreign retailers. Pampering the Chinese consumers by multinational 
retailers has had interesting results, as one supervisor noted: "In China, if somebody spends one yuan, they want one thousand yuans of service" (Gamble and Huang, 2008).

In sum, the highly competitive retailing environment is forcing retailers to heed a basic admonition to survive and prosper: identify ways to enhance customer satisfaction and customer loyalty. Today, as customers are given an array of choices by retailers and wooed to make purchases by them, the customer indeed has become king. The customer now has unparalleled discretion in terms of what to buy, what not to buy, from where and when. To survive and prosper in this climate, a competitive retailer must always strive to achieve maximum customer satisfaction since it serves as a driver to gain customer loyalty. Indeed, offering superior quality service is essential to maximise customer satisfaction and loyalty. Retailers who make the right investments in training store personnel, creating an appealing shopping environment and having the right product mix will stand out in the retailing crowd. Understanding the customer and his/her perceptions of service quality should be a major prerequisite before these investments are made. Most importantly, this understanding should also focus on the deficiencies that consumers experience with competitors in the quality of services they offer. Entrepreneurs who have keen acumen in understanding service quality can prosper in this milieu. Such entrepreneurs may be more adaptable and not prone to being blind sighted by conventional approaches to retailing; instead, they can find ways of delivering service quality that can delight customers. Delighted customers then become major apostles or promoters in spreading strong word-of-mouth advertising to attract new customers. In the USA, Costco is one store that seems to have an entrepreneurial zeal in how it keeps customers happy and coming back to the store.

\section{Measurement of service quality}

To distinguish themselves from competitors, retailers not only have to provide a better service, but also measure whether consumers have a favourable evaluation of their service. Measuring quality perceptions at the retail level permits retailers to determine if shoppers are satisfied with their shopping experiences; if inadequacies are identified, retailers can implement strategies to correct such problems. One measure that has been extensively used for this purpose is the service quality scale (SERVQUAL). Developed by Parasuraman et al. (1991), the SERVQUAL scale comprises 22 items to measure consumers' service expectations (e.g., 'excellent stores' physical layout will be visually appealing', 'employees of excellent stores will be appearing neat'). The same 22 items are reworded to measure perceptions of actual service rendered by service providers ('the ___ retail store's physical layout is visually appealing, 'the employees of retail store are neat appearing'). For each scale item, the difference between the expectation score and perception score is the gap score which reflects the service quality gaps. There are a total of 22 gap scores, given the 22 -item scale.

Based on factor analysis of several applications of the scale, Parasuraman et al. (1991) identified that the SERVQUAL scale has five dimensions: tangibles, reliability, responsiveness, assurance and empathy. Subsequently, other studies applied the SERVQUAL scale in both the B2C and B2B sectors. In this process, several questions arose concerning the dimensionality of the scale (Babakus and Boller, 1992). The usefulness of the gap scores (i.e., the difference between service quality expectations and service quality perceptions) as measures of service quality was also questioned by some 
researchers on conceptual and empirical grounds. For example, Brown et al. (1993) showed that gap scores in general demonstrate poor reliability. The construct validity of gap scores is also suspect because gap scores would have a theoretically high correlation with their component scores (e.g., perceptions and expectations). As a result, gap scores are not likely to be distinct from their component scores. Empirically, Babakus and Boller (1992) and Cronin and Taylor (1992) showed that the perceptual components of SERVQUAL outperformed the gap scores in predicting overall service quality, suggesting that service quality is best measured by perceptions than by gap scores.

Despite some limitations of the SERVQUAL scale, the impact of the scale in the area of service quality measurement is widely accepted. Even its major critics acknowledge its popularity. Buttle (1996) and Yuksel and Menderes (2001) contend that SERVQUAL is a helpful operationalisation of a somewhat nebulous construct, service quality. Most importantly, an alternative to SERVQUAL with the same level of general appeal and research dominance has yet to appear. Hence, the authors feel justified in using the SERVQUAL scale as the metric of service quality. Further, it is not known whether and to what extent a scale that was developed and tested extensively in the USA has potential for application cross-nationally in the retail setting. To address this gap in the literature, we examined the service quality in one particular type of retailing, namely department stores in Singapore.

The objective of this paper is two pronged. First, we establish the psychometric properties of the SERVQUAL scale to demonstrate that it is a sound metric for measuring service quality at the retail level. Unless the scale has strong psychometric properties, its usage is questionable. Second and more importantly, we apply this scale to the Singapore retail sector to compare service quality expectations, perceptions and gap scores by gender, age and shopping frequency.

\section{Method}

The data was collected in Singapore and administered to consumers near shopping centres throughout Singapore who were engaged in the shopping environment. The survey was personally administered in English and took about ten minutes to complete. Personal interviewers were present at the time that the subjects completed the survey. Even though the sample was a convenience sample, every effort was made to collect data from various demographic groups. However, older consumer groups were represented less frequently than younger consumers. The overall sample size for the survey was 172 .

The survey consisted of the adapted version of the 22-item service quality scale known as SERVQUAL scale (Parasuraman et al., 1991). It measures various aspects of service such as tangibles, reliability, responsiveness, assurance and empathy. Survey participants provided the expected quality they deemed necessary from retailers and subsequently the actual service quality rendered by Singaporean retailers in general. Seven point rating scales $(1=$ low, $7=$ high $)$ were used to measure response to each of the 22 -scale items. The survey also measured overall satisfaction with retailers, also using a seven-point rating scale. The demographic characteristics included measures of age, gender and shopping frequency.

Descriptive statistics reveal that the sample included a good representation of either gender group, with females constituting $59 \%$ of the sample. The sample also included 
people from different age groups. While younger consumers between 18 and 24 represented the bulk of the sample (50\%), $25 \%$ of the sample was between 25 and 34 , $14 \%$ was above 35 and $11 \%$ was below 18 years old. The shopping frequency of the sampled consumers ranged from at least once a week (22.1), once in two weeks (38.4\%), once in a month $(25.6 \%)$ and less than once a month (14\%). In sum, the sample consisted of a cross-section of people of different age and gender groups of the Singaporean population.

\section{Results}

The main objective of our paper is to examine service quality of retailers in terms of consumer expectations of retailer service, perceptions of actual level of service received and the gap in service quality. We also wanted to find out whether service quality varies by age, gender and shopping frequency. To make these comparisons, we first needed to examine the psychometric properties of the service quality measures. We accomplished this task by performing a series of confirmatory factor analyses using Lisrel 8.80 statistical software (Joreskog and Sorbom, 2006).

\subsection{Psychometric properties of service quality measures}

First, we assessed the psychometric properties of SERVQUAL when applied to measure service quality of retailers in Singapore. Analyses were performed on SERVQUAL expectation, perception and gap scores. The gap scores were obtained by subtracting perceptions of actual service provided (i.e., perception scores) from the expected level of service expected by customers from the best service provider (expectation scores). The psychometric analyses examined the following questions:

a Does the SERVQUAL scale exhibit the same five-dimensional factor structure (representing the dimensions of tangibles, reliability, responsiveness, assurance and empathy) in the retailing context in Singapore?

b Is the SERVQUAL measure internally consistent? Do the items of each SERVQUAL dimension provide a reliable measure of that dimension?

c Do the five dimensions of the SERVQUAL measure exhibit convergent validity?

d Are the five SERVQUAL dimensions indeed distinct from each other and exhibit discriminant validity?

e Does the SERVQUAL measure predict overall customer satisfaction with the service provider? Which measure of service quality (i.e., perceptions, expectations or the gap scores) has the better predictive ability?

\subsubsection{Dimensionality}

The dimensionality of the SERVQUAL scale was assessed by comparing the fit of the hypothesised model for that scale with a number of other competing models. As applied to consumer services, the SERVQUAL measure developed by Parasuraman et al. (1991) represented five dimensions: tangibles, reliability, responsiveness, assurance and 
empathy. Hence, we considered the five-factor SERVQUAL measure as the initial hypothesised model to be tested. Several competing models of SERVQUAL measure were also examined. For example, in a subsequent study, Parasuraman et al. (1991) performed factor analysis and found that items representing responsiveness and assurance loaded on the same factor. Based on these findings, an alternative model is the four-factor model where responsiveness and assurance dimensions were combined to form one factor. An extension of this model is the three-factor model, where in addition to the separate tangibles and reliability factors, responsiveness, assurance and empathy were combined to form the third factor.

Table 1 Psychometric analysis of the service quality scale

\begin{tabular}{|c|c|c|c|c|c|}
\hline \multicolumn{6}{|c|}{ Dimensionality and fit statistics for the SERVQUAL scale } \\
\hline & $\chi^{2}(d f)$ & $\chi^{2} / d f$ & CFI & $T L I$ & Std. RMR \\
\hline \multicolumn{6}{|l|}{ Perceptions } \\
\hline 5 factors & $530.64(199)$ & 2.67 & .86 & .83 & .07 \\
\hline 4 factors & $564.90(203)$ & 2.78 & .84 & .82 & .07 \\
\hline 3 factors & $631.26(206)$ & 3.06 & .82 & .79 & .08 \\
\hline \multicolumn{6}{|l|}{ Expectations } \\
\hline 5 factors & $376.32(199)$ & 1.89 & .91 & .90 & .05 \\
\hline 4 factors & $392.21(203)$ & 1.93 & .90 & .89 & .05 \\
\hline 3 factors & $425.64(206)$ & 2.07 & .89 & .88 & .06 \\
\hline \multicolumn{6}{|l|}{ Gap scores } \\
\hline 5 factors & $406.59(199)$ & 2.04 & .88 & .86 & .07 \\
\hline 4 factors & $415.40(203)$ & 2.05 & .88 & .86 & .07 \\
\hline 3 factors & $444.10(206)$ & 2.16 & .86 & .85 & .07 \\
\hline \multicolumn{6}{|c|}{ Reliability and construct variance for SERVQUAL dimensions } \\
\hline & Tangibles & Reliability & Responsive & Assurance & Empathy \\
\hline \multicolumn{6}{|l|}{ Perceptions } \\
\hline Reliability & .73 & .88 & .83 & .86 & .85 \\
\hline Var explain & .43 & .59 & .57 & .61 & .55 \\
\hline \multicolumn{6}{|l|}{ Expectations } \\
\hline Reliability & .73 & .83 & .84 & .81 & .86 \\
\hline Var explain & .48 & .50 & .56 & .53 & .56 \\
\hline \multicolumn{6}{|l|}{ Gap scores } \\
\hline Reliability & .69 & .82 & .80 & .81 & .83 \\
\hline Var explain & .38 & .48 & .50 & .52 & .51 \\
\hline
\end{tabular}

Table 1 provides several fit indices used for evaluating the various competing models of the SERVQUAL measure. Examining the SERVQUAL perception scores first, the $\chi^{2}$ fit of the hypothesised (five-factor) model $\left(530.64,199 \mathrm{df}\right.$ ) was compared to the $\chi^{2}$ fit of the four-factor model $(564.90,203 \mathrm{df})$. The fit of the five-factor model was significantly different from that of the 4 -factor model $\left(\chi^{2}\right.$ diff. $=34.26$, df. $\left.=4, p<.05\right)$, implying that the five-factor model was a better representation of SERVQUAL dimensionality than the 
four-factor model. Next, the four-factor model was compared to the fit of the three-factor model $\left(\chi^{2}=631.26, \mathrm{df} .=206\right)$. The difference in $\chi^{2}$ fit between these two models $(66.26$, $3 \mathrm{df})$ was also significantly different $(\mathrm{p}<.05)$, implying that the five-factor model is preferred. Hence, the $\chi^{2}$ fit statistics supported the five-factor model representing the dimensions of tangibles, reliability and the combination of responsiveness, assurance and empathy.

The use of $\chi^{2}$ fit statistics for comparing the fit of alternative models was criticised by some researchers (cf. Marsh, 1994) because the $\chi^{2}$ value is sensitive to sample size and for larger samples, even a small degree of lack of fit becomes statistically significant. This would lead to the rejection of a more parsimonious model (e.g., two-factor or one-factor models) in favour of a less parsimonious or a more elaborate model (e.g., three-factor model). Hence, to overcome this problem, a variety of other fit indices were examined as seen in Table 1. Specifically, the fit indices considered in this study were the root-mean-square residual (RMR), the $\chi^{2} / \mathrm{df}$ ratio, comparative fit index (CFI), and the Tucker-Lewis index (TLI). Most of these indices were available as part of the Lisrel output. Bollen and Long (1993) compiled articles from researchers who evaluated most of the above fit indices. When examining the above fit indices, CFI and TLI values of .9 or above provide a good fit of the underlying model to the data. For RMR, a residual of .05 or implies a good fit and for $\chi^{2} / \mathrm{df}$ ratio, a value of 3 or less is preferred (cf. Byrne, 2001). When using these fit indices, it can be seen that for SERVQUAL perception scores, the five-factor model provided the best fit overall (vs. the four-factor model or the three-factor model), even though the fit indices suggested only a modest fit. This conclusion was because only one fit statistic, the $\chi^{2} / \mathrm{df}$ ratio, indicates a good fit. The fit indices were even less acceptable for the four-factor and three-factor models. This result implied that the SERVQUAL perceptions measure does have five dimensions as hypothesised, but the fit of the five-factor model is only modest.

When repeating this analysis for gap scores and expectations scores, the five-factor model again presented the best fit overall (based on the $\chi^{2}$ difference tests) as compared to the four-factor or three-factor models. In sum, the dimensionality tests indicate that, while the hypothesised five-factor model as conceptualised by Parasuraman et al. (1991) provides acceptable level of fit in terms of various fit indices, the quality of fit is modest at best.

\subsubsection{Reliability}

The composite reliability estimates (Fornell and Larcker, 1981), which are analogous to coefficient alpha, are presented in the second part of Table 1. For any SERVQUAL dimension, a reliability estimate of 0.7 or better is considered acceptable (Nunnally and Bernstein, 1994). For perceptions, expectations and gap scores, the reliability estimates of the five-factor model were generally acceptable. In sum, the reliability analysis provided support for the five-factor model.

\subsubsection{Convergent validity}

Convergent validity of the SERVQUAL perception and gap scores was examined next. This was done by computing the 'average variance extracted' by each SERVQUAL dimension from its underlying indicators. An average variance extracted of at least 0.50 (i.e., 50\%) provided support for convergent validity (cf. Fornell and Larcker, 1981). From 
examining the average variance extracted scores in Table 1, it was clear that with the exception of the tangibles dimension, these estimates are above 0.5 for the remaining dimensions of the SERVQUAL perception scores. The same conclusion also extended to expectation and gap scores. In sum, the convergent validity test provided moderate support for the five-factor model of SERVQUAL perception scores, expectation scores and gap scores.

\subsubsection{Discriminant validity}

The various dimensions of the SERVQUAL scale were considered to be distinct from each other (and exhibit discriminant validity), provided that the correlations among those dimensions were small and the confidence intervals around those correlations did not contain a value of ' 1 '. The correlations among the SERVQUAL dimensions for both perception and gap scores as well as the standard errors are provided in Table 2.

Table 2 Correlations and (standard errors) among service quality dimensions

\begin{tabular}{|c|c|c|c|c|}
\hline & Tangibles & Reliability & Responsiveness & Assurance \\
\hline \multicolumn{5}{|c|}{ 22-item perceptions scale } \\
\hline Reliability & $.62(.06)$ & & & \\
\hline Responsiveness & $.51(.07)$ & $.69(.05)$ & & \\
\hline Assurance & $.58(.07)$ & $.63(.06)$ & $.86(.03)$ & \\
\hline Empathy & $.38(.08)$ & $.64(.06)$ & $.77(.04)$ & $.90(.03)$ \\
\hline \multicolumn{5}{|c|}{ 22-item expectations scale } \\
\hline Reliability & $.36(.09)$ & & & \\
\hline Responsiveness & $.40(.09)$ & $.87(.04)$ & & \\
\hline Assurance & $.43(.08)$ & $.74(.05)$ & $.96(.03)$ & \\
\hline Empathy & $.47(.08)$ & $.69(.05)$ & $.87(.03)$ & $.95(.02)$ \\
\hline \multicolumn{5}{|c|}{ 22-item gap scores scale } \\
\hline Reliability & $.36(.09)$ & & & \\
\hline Responsiveness & $.43(.08)$ & $.76(.05)$ & & \\
\hline Assurance & $.43(.08)$ & $.61(.06)$ & $.86(.04)$ & \\
\hline Empathy & $.43(.08)$ & $.68(.06)$ & $.85(.04)$ & $.95(.03)$ \\
\hline
\end{tabular}

Note: Across the three scales, the correlations among responsiveness, assurance and empathy are very high.

As shown in Table 2, the correlation between tangibles and reliability was .62 for perception scores (standard deviation - .06). The confidence interval around this correlation was .56 to .68. Clearly, this interval did not contain 1. Hence, support exists for discriminant validity of these two dimensions, tangibles and reliability, when only looking at perception scores. From Table 2, we can see that the same conclusion applies to expectation scores and gap scores. Other results indicate, however, that there were fairly high correlations among responsiveness, assurance and empathy dimensions. These results were consistent even when considering expectations scores and gap scores. So, it appears that responsiveness, assurance, and empathy dimensions exhibited only a modest level of discriminant validity. 
Table 3 Correlations of SERVQUAL dimensions with satisfaction

\begin{tabular}{lccc}
\hline & Perceptions & Expectations & Gap scores \\
\hline Tangibles & .33 & $.09^{*}$ & -.19 \\
Reliability & .31 & .23 & $-.07^{*}$ \\
Responsiveness & .32 & .23 & $-.06^{*}$ \\
Assurance & .25 & .26 & $.00^{*}$ \\
Empathy & .29 & .16 & $-.09^{*}$ \\
Overall scale & .37 & .26 & $-.10^{*}$ \\
\hline & Mean values of SERVQUAL dimensions & \\
\hline Tangibles & 5.04 & 5.55 & 0.51 \\
Reliability & 4.60 & 5.72 & 1.12 \\
Responsiveness & 4.60 & 5.65 & 1.07 \\
Assurance & 4.51 & 5.60 & 1.08 \\
Empathy & 4.35 & 5.32 & 0.97 \\
Overall scale & 4.61 & 5.60 & 0.99 \\
\hline
\end{tabular}

Note: $*$ Indicates that the corresponding correlation between the service quality dimension and satisfaction is not significant at .05 level.

\subsubsection{Predictive ability}

The ability of the SERVQUAL measure in predicting the overall evaluation of service was examined next. For each of the SERVQUAL dimensions, its correlation with the overall evaluation of service was computed for perceptions, expectations, and gap scores (see Table 3 for results). These correlations for SERVQUAL perceptions scores ranged from .25 to .33 ; all correlations are statistically significant $(\mathrm{p}<.05)$. For SERVQUAL expectations, only the correlation between tangibles and service satisfaction was not significant, the remaining ones were significant. However, the gap scores did not correlate significantly with service satisfaction. Overall, then, perceptions and expectations were better predictors of service satisfaction than gap scores.

In sum, results provide arguably sufficient support for the psychometric properties of the service quality scale, whether we consider perceptions, expectations or gap scores. Given this support, we proceeded to compute average or mean scores of the five service quality dimension for perceptions, expectations and gap scores. These results are shown in the second part of Table 3. Results indicate that consumers of Singapore retail stores perceived significant gaps in service quality, the gap being the highest for reliability, responsiveness and assurance dimensions. Next, we examined whether these results vary by gender, shopping frequency and age of consumers.

\subsection{Gender differences}

Figure 1 shows gender differences in service quality opinions. In Figure 1(a), the top part of the hi-lo chart shows mean service expectations and the bottom part shows mean service perceptions. The length of the bar, which is the difference between service expectations and perceptions reflects gap in service quality. This gap in service quality is also shown as a line chart in Figure 1(b). From Figure 1(a), it is clear that overall 
Singapore retailers scored above average on all aspects of service quality, as the mean scores on seven-point rating scales $(1=$ low, $7=$ high $)$ were consistently above the scale midpoint of 4 . However, there were significant gaps in service for all aspects of service quality, as service expectations were consistently above perceptions of actual service delivered. These results were similar for both males and females.

Figure 1 (a) Mean expectations and perceptions of retailers' service by gender (b) mean service quality gap scores by gender (see online version for colours)

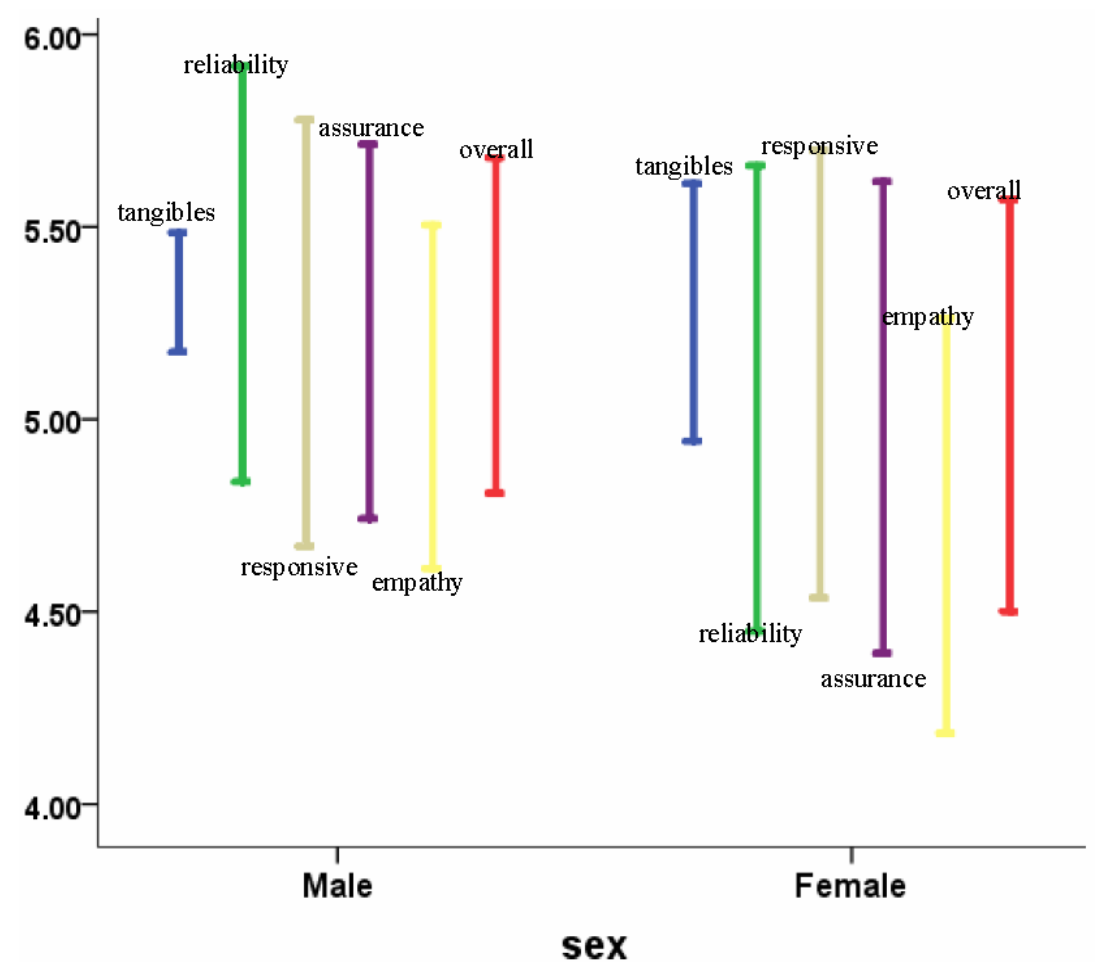

(a)

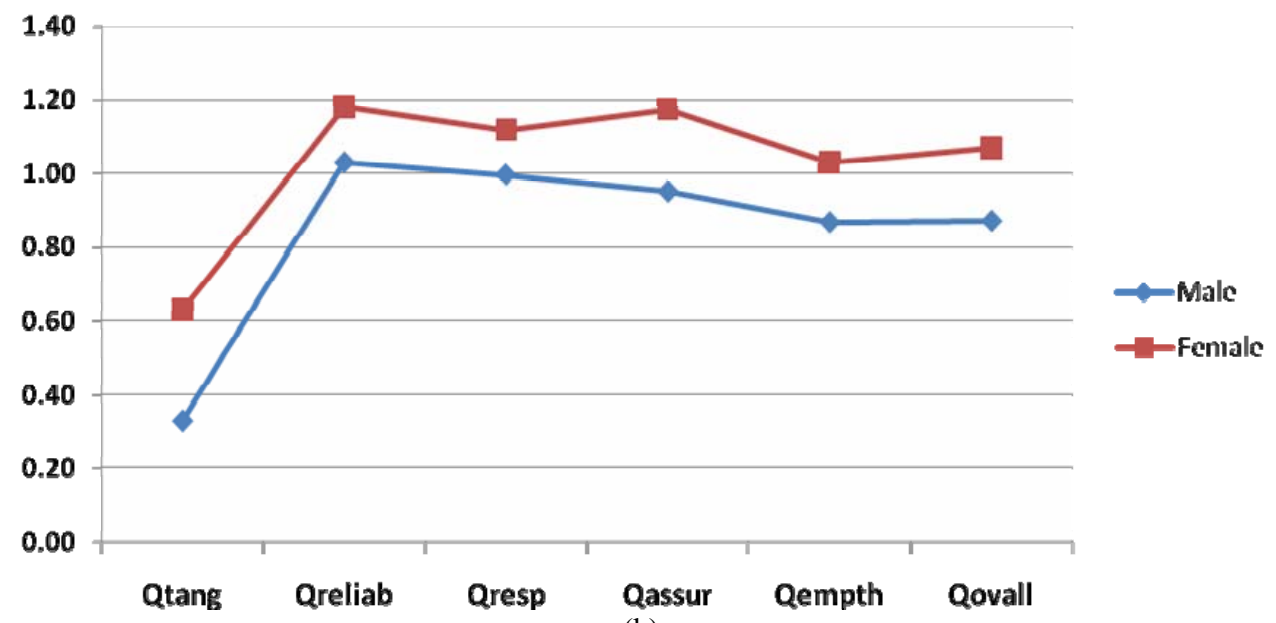

(b) 
Figure 2 (a) Mean expectations and perceptions of retailers' service by shopping frequency (b) mean service quality gap scores by shopping frequency (see online version for colours)

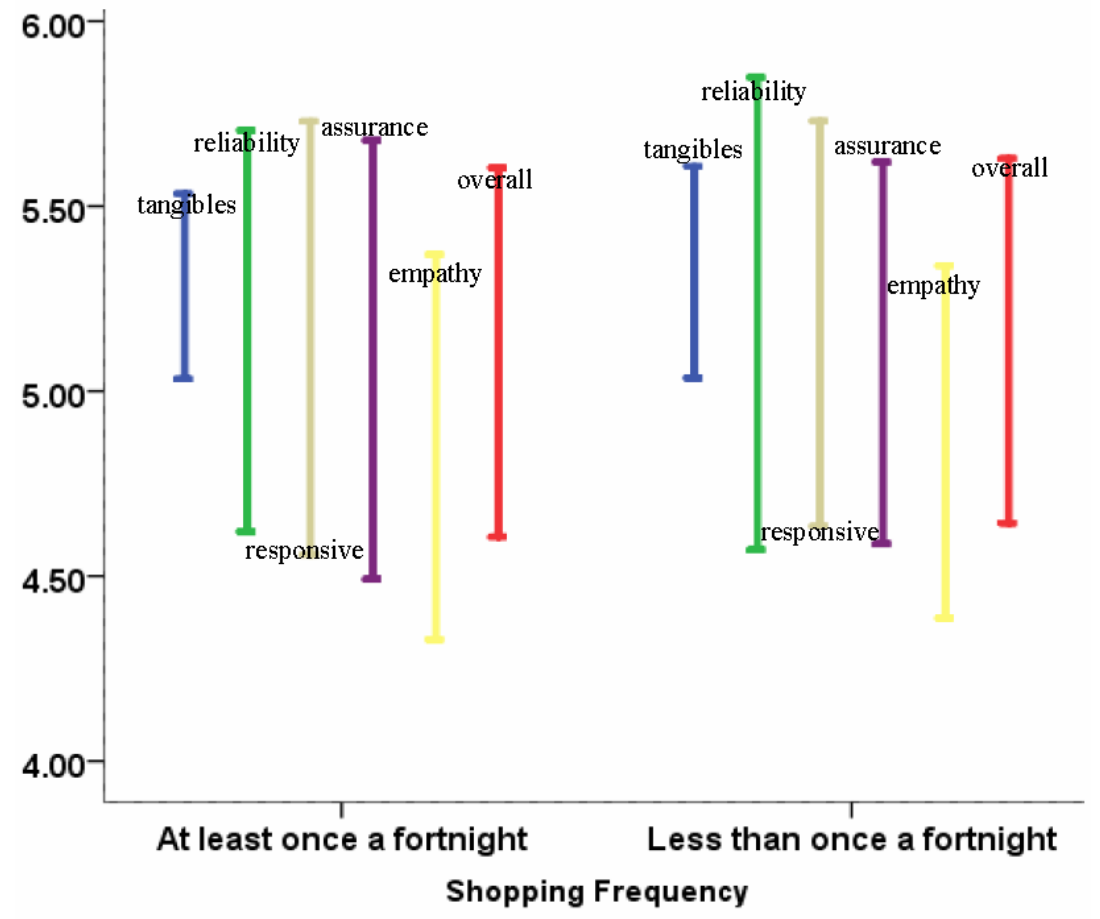

(a)

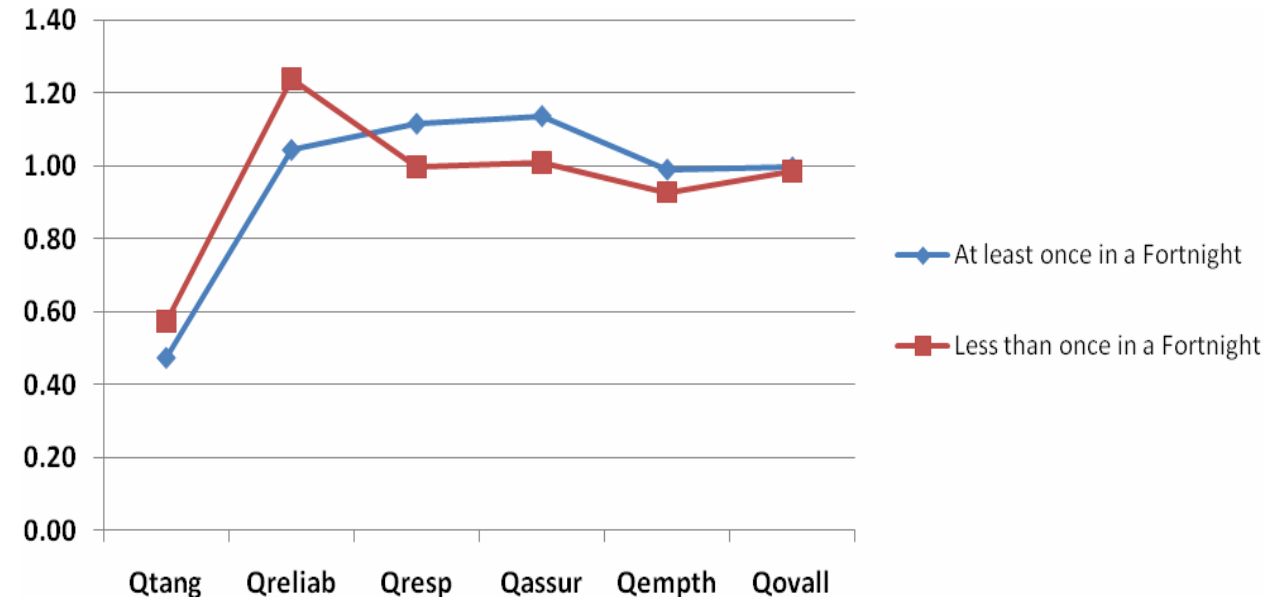

(b)

To gain additional perspective, we performed repeated measures analysis of variance, with the gap scores on the five service quality dimensions as the within-subjects factor and gender as the between-subjects factor. Results indicated that gender did not have a 
significant impact $(\mathrm{F} 1,159=1.74, \mathrm{p}$-value $=.19)$; the gap scores were not different significantly for males and females. However, the within-subjects factor is significant $(\mathrm{F} 4,156=12.02$, prob. $=.00)$, implying that the gap in service quality was significantly higher for some of the service quality dimensions as compared to the others. As shown in Figure 1(b), the gap in quality was relatively shorter for the tangible aspects of service, but much higher for reliability, responsiveness and assurance. Analyses did not reveal any gender by within-subject factor interaction $(\mathrm{F} 4,156=.59, \mathrm{p}=.70)$.

\subsection{Differences by shopping frequency}

Figure 2 shows differences in service quality opinions by consumers' shopping frequency. Similar to Figure 1(a), Figure 1(b) also is a hi-lo chart, showing service expectation means (upper end of the bar) and service perceptions (lower end of the bar). Even though all Singaporeans, irrespective of their shopping frequency, evaluated retailers' delivery of actual service above 4 on a seven-point rating scales $(1=$ low, $7=$ high), once again, both groups rated service expectations as much higher than service perceptions. This result indicates that significant gaps in service quality persist.

A repeated measures analysis of variance was performed next, with the gap scores of the five service quality dimensions serving as the within-subjects factor and shopping frequency serving as the between-subjects factor. Results supported a significant within-subject effect

$(\mathrm{F} 4,156=11.06, \mathrm{p}$-value $=.00)$, but no significant between-subject effect for shopping frequency $(\mathrm{F} 1,159=.94$, $\mathrm{p}$-value $=.61)$ and no significant interaction between shopping frequency and the within-subject factor $(\mathrm{F} 4,156=.93$, p-value $=.45)$. This outcome means that the gap in service quality was significantly higher for some service quality dimensions over the others. Further, these results were similar for frequent vs. infrequent shoppers, given the non-significance of the shopping frequency effect. Figure 2(b) reveals that the service quality gap was high for the dimensions of reliability, responsiveness and assurance as compared to tangibility. The gap was also relatively higher for assurance and empathy over tangibility.

\subsection{Differences by age}

Figure 3 shows results of analysis by age. To obtain insightful results, the older consumers ( 25 and above) were combined into one group. The results, presented in Figure 3, compared three age groups - those under 18,18 to 24,25 and above. Parenthetically, the results were similar even if the older consumer groups ( 25 to 34,35 to 44,45 and above) were to be treated separately. As shown in Figure 3(a), service expectations and perceptions were above the scale neutral point of 4 for all age groups, implying that all age groups viewed Singapore retailers' service positively. However, they expected better service. Interestingly, the younger consumers' (i.e., those below 18) expectations are relatively lower as compared to the other age groups. However, they also have relatively lower service expectations. One noteworthy finding was that those under 18 had low perceptions for the empathy dimension. It appeared that those under 18 feel the retailers were not providing them personal attention, care and were not attending to the personal needs of the youngest consumer segment. 
Figure 3 (a) Mean expectations and perceptions of service quality by age (b) mean service quality gap scores by age (see online version for colours)

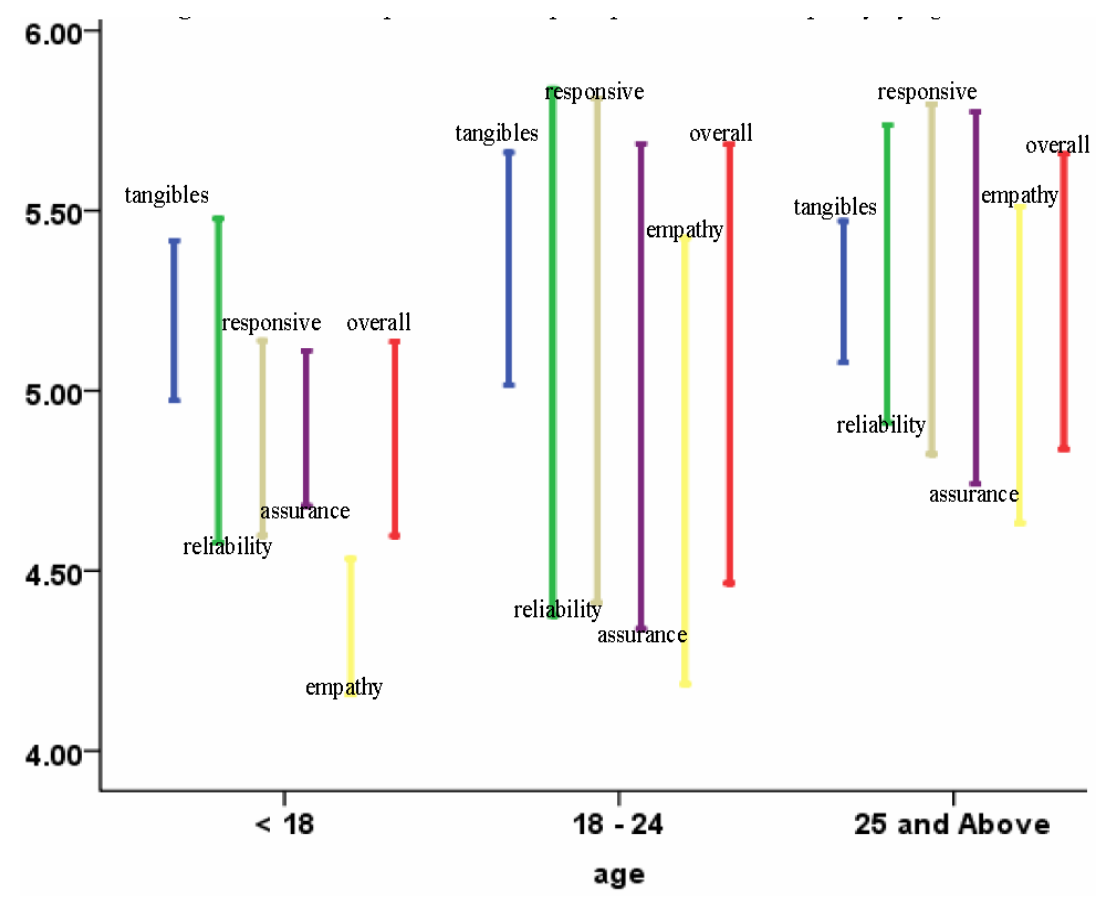

(a)

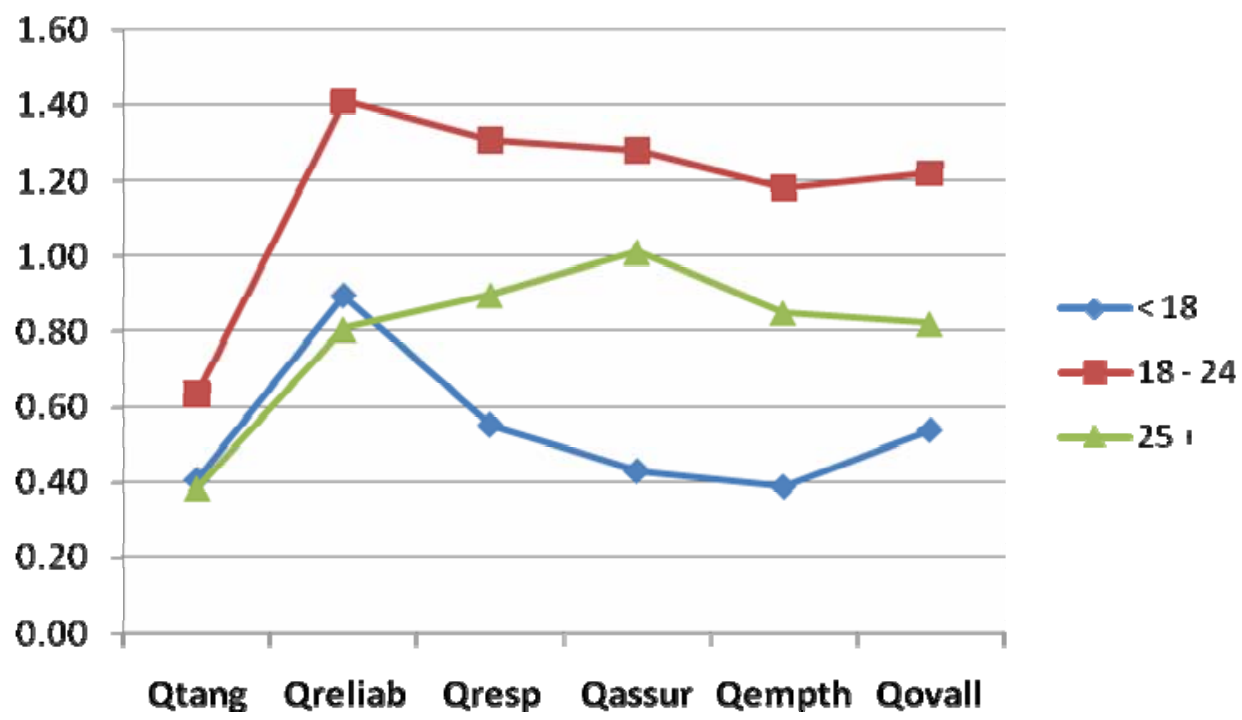

(b)

Figure 3(b) shows service quality gap scores for the three age groups. Clearly, the 18-24 age group, the so-called Generation Y consumer group which is the most sought after segment by marketers for their spending habits and purchasing power, were least 
satisfied with the retailer service as compared to the other groups. That result occurred because this group perceived significantly large gaps in retailer service quality. Repeated measures analysis of variance supported this finding; age did have a significant impact on service quality gap scores $(\mathrm{F} 2,158=6.01$, p-value $=.00)$. We also found significant impact of within-subject factor effect $(F 1,115=5.85$, p-value $=.00)$, implying that the gap scores were significantly higher for some service quality dimensions than the other. From Figure 3(b), we can see that perceptions in quality gap were higher for reliability followed by responsiveness, assurance and empathy. They were relatively much lower for tangible aspects of service.

\section{Discussion}

The retail scene in Singapore is expected to boom over the next few years. It has long been viewed as a shoppers' paradise for visitors from countries such as Japan and Taiwan. Singapore has the excellent opportunity to become the leading destination for shopping in Asia and one of the leaders in the world (Boon, 2007). To realise this potential and keep its reputation as a premier retail destination, it is urgent that Singaporean retailers be attentive to the perceptions of quality among shoppers. Entrepreneurs wishing to start new retail operation should be especially attentive to the findings of this study. Failure to plan is indeed planning to fail if retailers do not study the gaps in quality and then take appropriate measures to remedy the inadequacies. The use of metrics such as SERVQUAL can be used to gauge such quality perceptions; these measures must be done on a frequent and periodic basis.

The results by gender, age and shopping frequency reinforce the view that while retailers in Singapore are perceived as providing good service quality, consumers expect even better levels of service. According to the results, retailers should make attempts to increase the reliability of service; they should be more responsive to shopper needs and display a caring attitude towards consumers. While retailers may think that redesigning their outlets and modernising them with attractive features may be enough to gain a competitive edge in the hotly contested retail sector, our results indicate that it is the non-tangible aspects of services that are likely to win over customers. The results clearly sound warning bells for Singapore retailers, particularly if they are attempting to market to the younger 'Generation Y' consumers in the 18 to 24 year age group. Entrepreneurial retailers interested in focusing on these demographics would do well to accommodate the expectations of this age group in how they deliver service quality.

\section{Future research}

Future research needs to continue on the retail environment in Singapore. More attention needs to focus on how quality perceptions translate into store loyalty, favourable word-of-mouth and satisfaction. How to identify the 'wow' dimensions in service quality that can excite customers and increase their patronage is a critical research area. Another realm of research deals with the different perceptions of quality according to the various consumer segments that exist. What are the expectations of these various segments (such as locals vs. tourists) and what changes in service quality are needed to keep them excited 
about the store and their desire to shop there? The last area for research focuses on the quality strategies that overseas entrants are using in the Singapore retail market to steal market share from established, domestic retailers. Since many companies are looking to expand overseas, Singaporean retailers must be vigilant to preempt them from overpowering them and taking their established customers and those that visit as tourists.

\section{References}

Anderson, C. and Zeithmal, V.A. (1984) 'Stage of the product life cycle, business strategy and business performance', Academy of Management Journal, March, Vol. 27, pp.5-24.

Azhar, A. (2005) 'Winning ways to outsmart the competition - a retailer's survival guide', Retail World, Vol. 58, No. 1, p.18.

Babakus, E. and Boller, G.W. (1989) 'An empirical assessment of the SERVQUAL scale', Journal of Business Research, Vol. 24, pp.253-268.

Bollen, K.A. and Long, J.S. (1993) Testing Structural Equation Models, Sage Publications, Newbury Park, CA.

Boon, P.C. (2007) 'Opening address to the Singapore retail industry conference', Suntec International Convention and Exhibition Centre, Singapore, 26 September.

Brown, T.J., Churchill, G.A. and Peter, J.P. (1993) 'Improving the measurement of service quality', Journal of Retailing, Vol. 69, No. 1, pp.127-139.

Buttle, F. (1996) 'SERVQUAL: review, critique, research agenda', European Journal of Marketing, Vol. 30, No. 1, pp.8-32.

Byrne, B.M. (2001) Structural Equation Modeling with AMOS, Lawrence Erlbaum Associates, Mahwah, NJ.

Cronin, J.J. Jr. and Taylor, S.A. (1992) 'Measuring service quality: a re-examination and extension', Journal of Marketing, July, Vol. 56, pp.55-68.

Fornell, C. and Larcker, D. (1981) 'Evaluating structural equation models with unobservable variables and measurement error', Journal of Marketing Research, February, Vol. 18, pp.39-50.

Gamble, J. and Huang, Q (2008) 'British and Japanese multinational retail firms and the development of consumer culture in China', available at http://www.consume.bbk.ac.uk/researchfindings/CofC_Findings_Gamble02.pdf [accessed on 1 November 2008].

Global Entrepreneurship Monitor Report (2006) Available at http://www.gemconsortium.org/download/1225051208379/GEM_2006_Global_Results_Sum mary_V2.pd, [accessed on 1 November 2008].

Ibrahim, M. and Ng, C. (2002) 'Determinants of entertaining shopping experiences and their link to consumer behavior: case studies of shopping centres in Singapore', Journal of Leisure Property, Vol. 2, No. 4, pp.338-357.

Joreskog, K.G. and Sorbom, D. (2006) Lisrel 8.80 for Windows, Scientific Software International, Lincolnwood, IL.

Kam, W.P. and Ping, H.Y. (2004) 'Profile of business angels in Singapore', available at http://www.nus.edu.sg/nec/research/rschdwload_pdf/BANSEASG\%20Business\%20Angels\%202000-03.pdf [accessed on 1 November 2008]

Kearney, A.T. (2005) 'Emerging market priorities for global retailers', available at http://www.atkearney.com/shared_res/pdf/GRDI_2005.pdf. [accessed on 1 November 2008].

Keri, D. (1993) 'Retailing in Singapore: coping with change', International Journal of Retail and Distribution Management, Vol. 21, No. 1, pp.10-21.

Marsh, H.W. (1994) 'Confirmatory factor analysis models of factorial invariance: a multifaceted approach', Journal of Structural Equations Modelling, Vol. 1, pp.5-34. 
Mehta, S.C. and Durvasula, S. (1998) 'Relationships between SERVQUAL dimensions and organizational performance in the case of a business-to-business service', Journal of Business and Industrial Marketing, Vol. 13, No. 1, pp.40-53.

Nunnally, J.C. and. Bernstein, I.H. (1994) Psychometric Theory, McGraw-Hill, New York.

Parasuraman, A., Berry, L.L. and Zeithmal, V.A. (1991) 'Refinement and reassessment of the SERVQUAL scale', Journal of Retailing, Vol. 67, No. 4, pp.420-450.

Phillips, L.W., Chang, D.R. and Buzzell, R.D. (1983) 'Product quality, cost position and business performance: a test of some key hypotheses', Journal of Marketing, Spring, Vol. 47, pp.26-43.

Wong, P.K., Lee, L., Ho, Y.P. and Wong, F. (2006) 'Global entrepreneurship monitor 2005 Singapore report', NUS Entrepreneurship Center.

Yap. C. (1996) 'Retailing and the retail space market in Singapore', International Journal of Retail and Distribution Management, Vol. 24, No. 8, pp.17-24.

Yuksel, A. and Menderes, A. (2001) 'The expectancy - disconfirmation paradigm: a critique', Journal of Hospitality and Tourism Research, Vol. 25, No. 2, pp.107-131. 